\title{
AIRPORT NOISE MODELLING FOR STRATEGIC ENVIRONMENTAL IMPACT ASSESSMENT OF AVIATION
}

\author{
Antonio J. Torija*, Rod H. Self and Ian H. Flindell
}

ISVR, University of Southampton, Highfield Campus, SO17 1BJ Southampton, UK

Author to whom correspondence should be addressed. Electronic mail:

$\underline{\text { A.J.Martinez@soton.ac.uk }}$

Tel.: +44 (0)2380592276 


\section{Abstract}

As projected by different agencies the aviation market will experience a significant increase in air traffic demand over the next decades, driven by the large demand of the Asia-Pacific region. To overcome the further deterioration of the quality of life of communities living around airports, the various aviation stakeholders are required to explore scenarios with different technology options, flight procedures, and fleet replacement strategies. Of course, the assessment of aviation scenarios must be addressed in a more integrated manner than hitherto, where noise, air quality and carbon release are considered. For such purpose, simplified airport noise models are required to overcome the important input data requirements and computation complexity of detailed airport noise models, and also to ensure compatibility against other environmental and economic models. This paper analyses the applicability and discusses the unavoidable limitations and advantages of existing simplified airport noise models within the context of multi-disciplinary strategic environmental impact assessment of aviation. Simplified airport noise models satisfying the above requirements and developed to be coupled with technology evaluators, e.g. Rapid Aviation Noise Evaluator (RANE) model [Torija et al., 2017], can inform policy decisions about which future technology platforms would be likely to be the most environmental efficient when considered holistically. Based on the specific conditions tested, the straight-out trajectory assumption and the use of generic aircraft types seems valid approximations for computing aviation noise outputs.

Keywords: Environmental noise; Environmental impacts; Air pollution; Aviation noise; Noise modelling. 


\section{Introduction}

To ensure the sustainability of the aviation sector, appropriate actions are required to mitigate community noise and air quality problems around airports, and to reduce fuel consumption. With the substantial increase in air traffic demand as forecast by several agencies [1-3], aviation industry is investing a significant effort in the development of ongoing research programs for enhancing fuel-burn efficiency, and reducing the mission of air pollutant and noise. Along this line, the Advisory Council for Aviation Research and Innovation in Europe (ACARE) and NASA have put forward fuel-burn and missions reduction goals for aircraft entering into service in the long-term: Flightpath 2050 [4] and N + 3 [5] programs respectively.

The assessment of the noise impact of future scenarios requires fleet-level studies where variables such as air traffic demand, fleet composition, technology options, and rate of penetration of novel aircraft are considered. Also, diverse flight procedures for minimising aircraft noise around airports will need to be assessed [6]. In these future scenarios, although there is an agreement that a considerable increase in air traffic will take place, the projections of different agencies differ significantly [1-3]; also, a large number of novel aircraft concepts under development or projected to be developed can be found in literature [7]. Therefore, the fleet-level prediction of noise for future scenarios is a highly combinatorial and computationally expensive problem, so that detailed airport noise models such as the FAA's Integrated Noise Model (INM) [8] or the UK Civil Aircraft Noise Contour Model (ANCON) [9] are not always practical at a fidelity-level required in preliminary strategic planning and decision making procedures [10]. For this reason, a number of simplified airport noise models for fleet-level studies have been developed. Although, each of these models compute noise outputs using a different approach, all of them are rapidly computable and have a simple formulation [11]. 
On the other hand, the decision on technology investment for minimizing environmental externalities of aviation requires an integrated and multi-disciplinary strategic environmental assessment. For this purpose, as proposed in this paper, airport noise models need to be incorporated in integrated tools [12] (Fig. 1), ensuring compatibility against input and output requirements in other environmental and economic models [13].

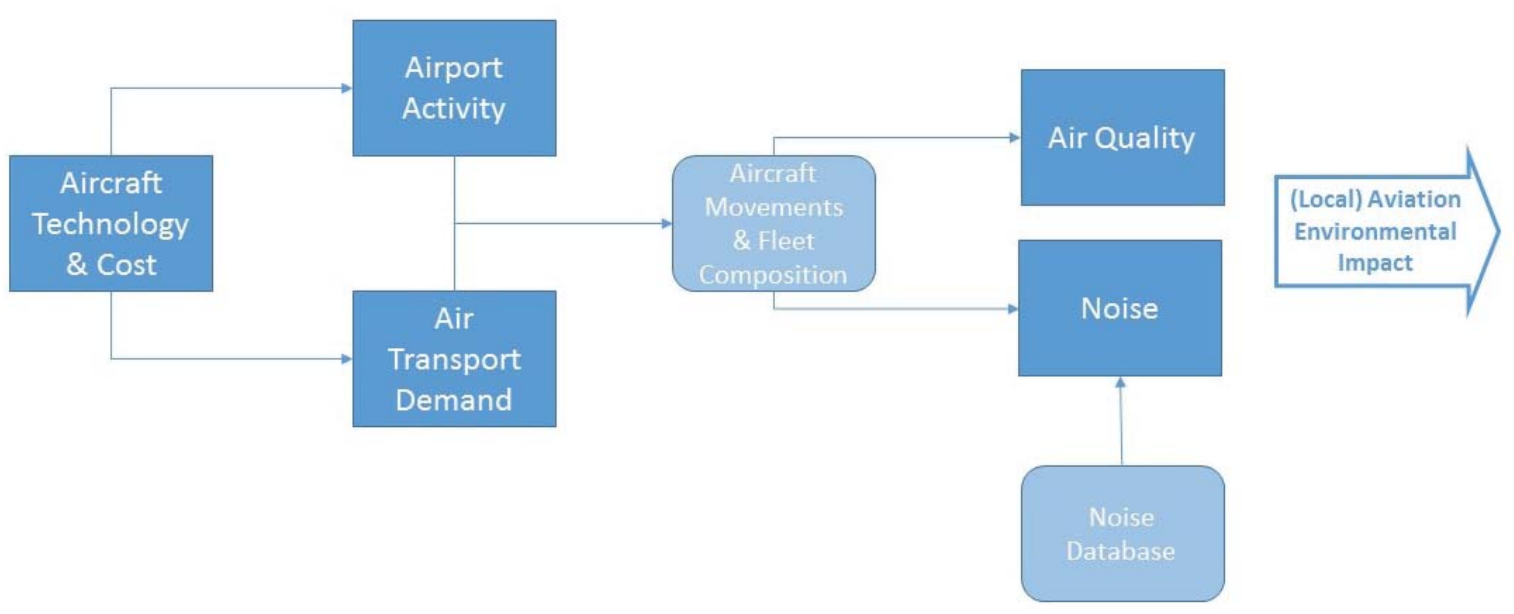

Fig. 1. Structure of an integrated model for assessing aviation environmental impact (modified from [12]).

This paper analyses the applicability of a number of simplified airport noise models within the context of strategic aviation environmental impact assessment, discussing their limitations and advantages. Moreover, this paper examines and discusses the validity of two common assumptions in most of the simplified airport noise models reviewed: (i) straight-in straight-out trajectory and (ii) generic vehicle used as representative of an aircraft category.

\section{Review of simplified airport noise models}


This section overviews some of the simplified airport noise models more often cited in the literature, describing their approach for computing noise outputs.

Powell [14] derived the analytical basis for relationship between noise contour areas and noise levels at certification measurement points.

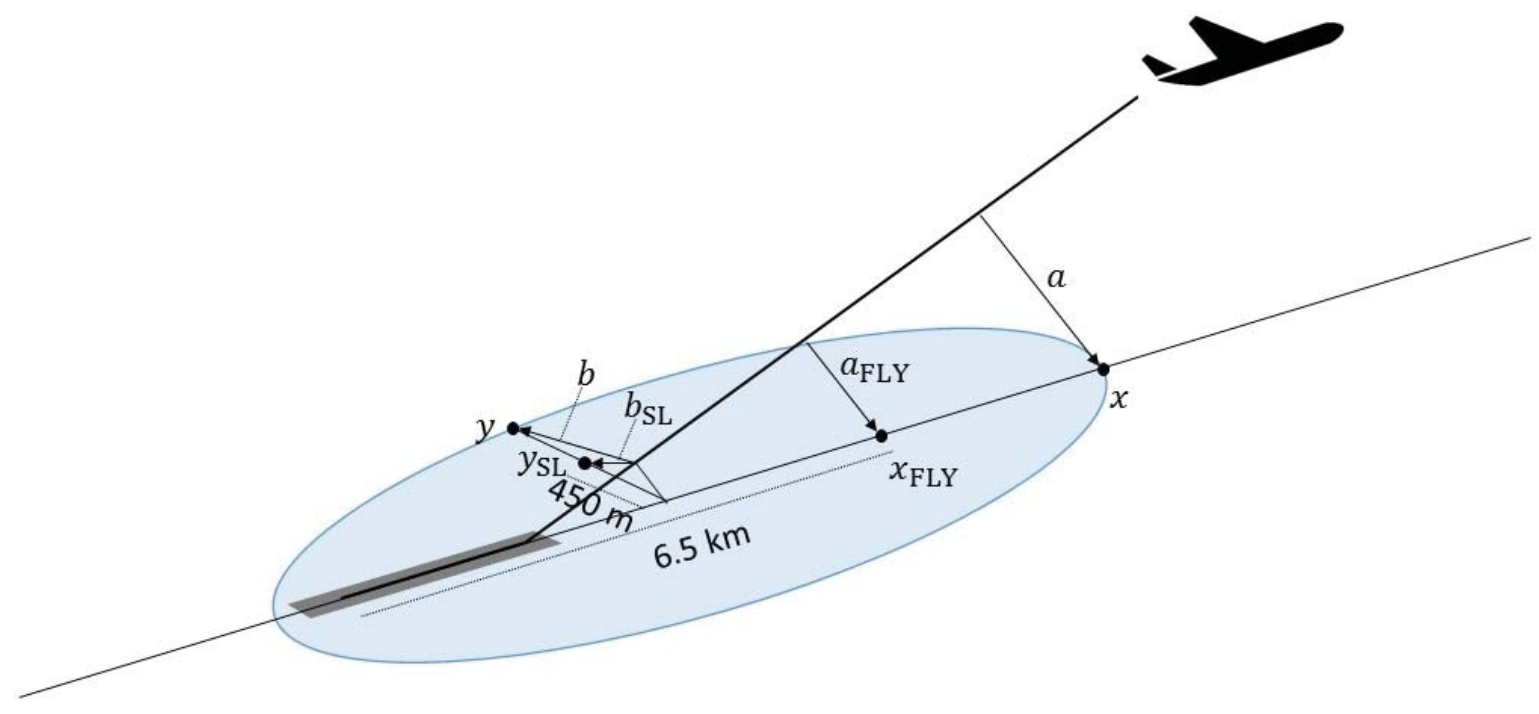

Fig. 2. Typical departure noise contour and geometric relationships to noise certification points (modified from [14]).

In Fig. 2, the sound-level at all points on the contour (outer line) is equal to a given value $L$, and the sound-levels at the flyover $\left(x_{F L Y}\right)$ and sideline $\left(y_{S L}\right)$ certification points are $L_{F L Y}$ and $L_{S L}$ respectively. For deriving this analytical basis:

(i) The power and acoustic output at the aircraft is assumed constant.

(ii) The sound-level is inversely proportional to distance assuming spherical spreading. Thus, 


$$
\begin{gathered}
L_{F L Y}=L+20 \cdot \log _{10}\left(a / a_{F L Y}\right) \\
L_{S L}=L+20 \cdot \log _{10}\left(b / b_{S L}\right)
\end{gathered}
$$

(iii) $x / x_{F L Y} \approx a / a_{F L Y}$ and $y / y_{S L} \approx b / b_{S L}$

(iv) The noise contour area is proportional to the product of the length and width parameters of the noise contour ( $x$ and $y$ in Fig. 2), and therefore,

$$
\text { Area } \propto\left(x_{F L Y} \cdot y_{S L}\right) \cdot\left[\frac{10^{\left(L_{F L Y}+L_{S L}\right) / 20}}{10^{(2 \cdot L) / 20}}\right]
$$

This section overviews some of the simplified airport noise models more often cited in the literature, describing their approach for computing noise outputs.

Dikshit and Crossley [8] developed a noise model that approximates INM-predicted area within the $65 \mathrm{~dB}$ Day-Night level (DNL) contour. Based on a set of INM noise experiments at a limited set of system airports, the noise model estimated the 65 (dBA) DNL contour area as a linear function of the number of aircraft operations (differentiating between passenger and cargo aircraft). The model uses the Noise Energy Equivalent (NEE) computed as $10^{E P N L / 10}$ from the published certification sound-levels at the flyover, sideline and approach certification points. The noise model also accounts for the effect of different Maximum Takeoff Weights (MTOW) on the takeoff sound-levels. This model was used to develop the noise module for a fleet-level evaluation of environmental impact of new aircraft [15].

The FAA's Area Equivalent Method (AEM) "is a mathematical procedure that provides an estimated noise contour area of a specific airport given the types of aircraft and the number of operations for each aircraft" [16]. Based on the concept of "equivalent operations" [10], the 
airport $65 \mathrm{dBA}$ DNL contour area is estimated for an equivalent number of operations of a reference aircraft [17]. The change in contour area is then determined by a scaling parameter relative to a change in number of operations [16]. AEM is used as a screening procedure to determine whether a detailed study (conducted with any detailed airport noise model, such as INM) is required.

Bernardo et al. [17] developed a noise model, called Airport Noise Grid Integration Method (ANGIM), where (single-event) aircraft departure and approach sound exposure levels (SEL) grids are pre-calculated assuming straight ground tracks and standard-day sea level atmosphere. Once the schedule of operations is defined, an airport-level SEL grid is computed as logarithmic additions of the SEL grids of all the events occurring during that flight schedule. For cases with multiple runways, the runway-level SEL grids are manipulated (rotated, translated and interpolated), and then summed to yield an airport-level SEL grid. Noise contour areas are then calculated from airport-level grids. This model was validated against INM, and also used for assessing fleet-level noise impacts of projected technology improvements [10].

Li et al. [18] developed a noise model for preliminary aircraft noise-reduction route design, named AIRNOISE. Although this model computes noise outputs using the same approach as detailed airport noise models [19] (SAE-AIR-1845), does not consider components related to terrain and atmosphere adjustments, thus reducing computation time.

Finally, Torija et al. [13] introduced an airport noise model named Rapid Aviation Noise Evaluator (RANE). Unlike grid-point based airport noise models which calculate noise contours from airport-level noise grids on the basis of logarithmic additions of all the events in a given flight schedule, RANE uses a more computationally efficient algorithm for calculating noise contour areas. On the basis of cylindrical (noise) surfaces formed around the flightpath and with a given "energy-equivalent" Noise Power Distance curve -NPD- (referred as Noise 
Radius, $\mathrm{R}_{\mathrm{N}}[20]$ ), a given noise contour is calculated as the intersection of each cylindrical surface with the ground (Fig. 3 top). Using sound-level integration at source, this "energyequivalent" NPD is computed for the combination of all the aircraft operations in a given flightpath. Although the aircraft was assumed to represent a moving isotropic noise source, which is a reasonable assumption for current aircraft, the analytical method underlying RANE allows the extension to an anisotropic noise source by replacing cylinders with some other shape of noise surface around the flightpath.

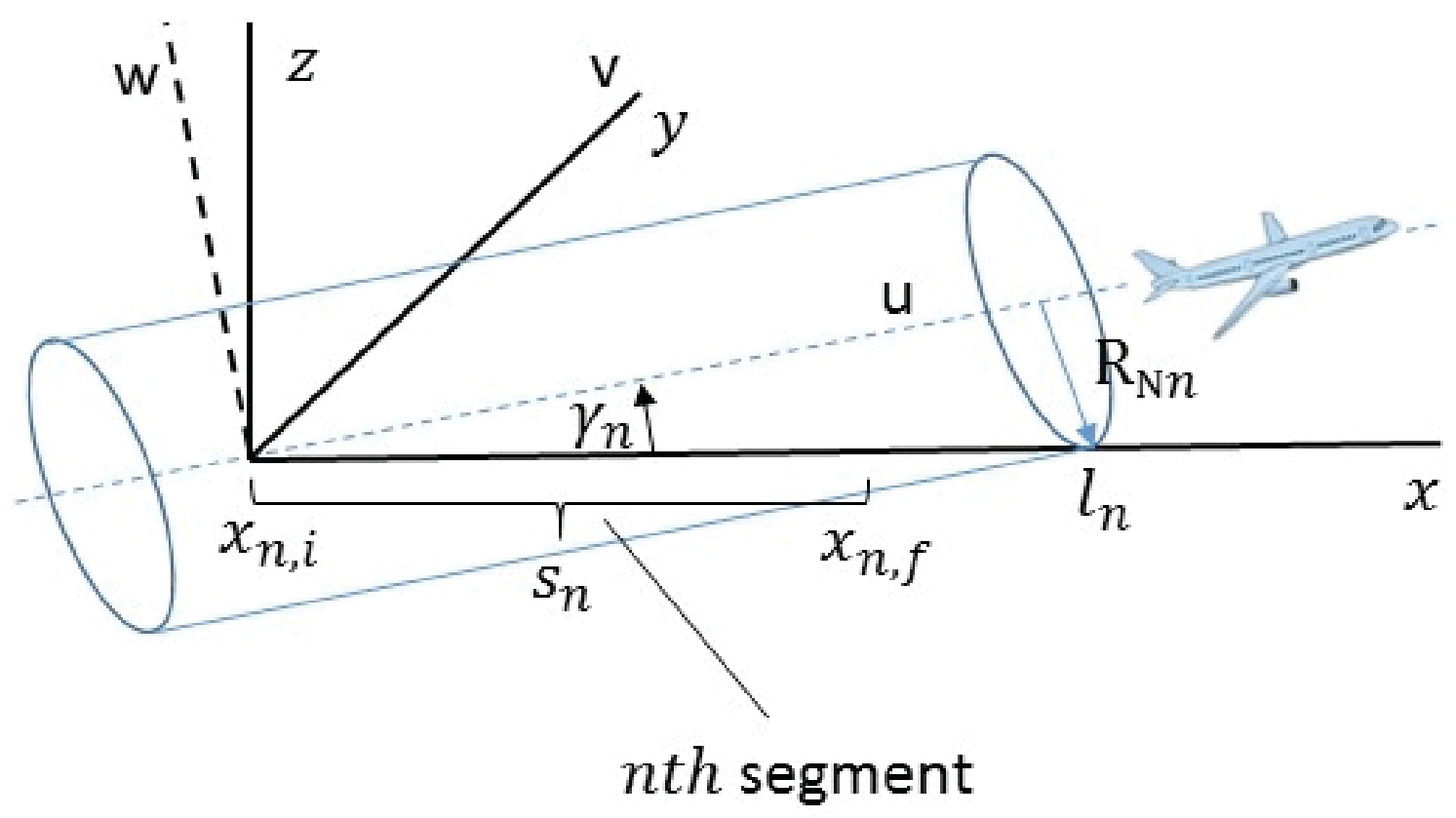




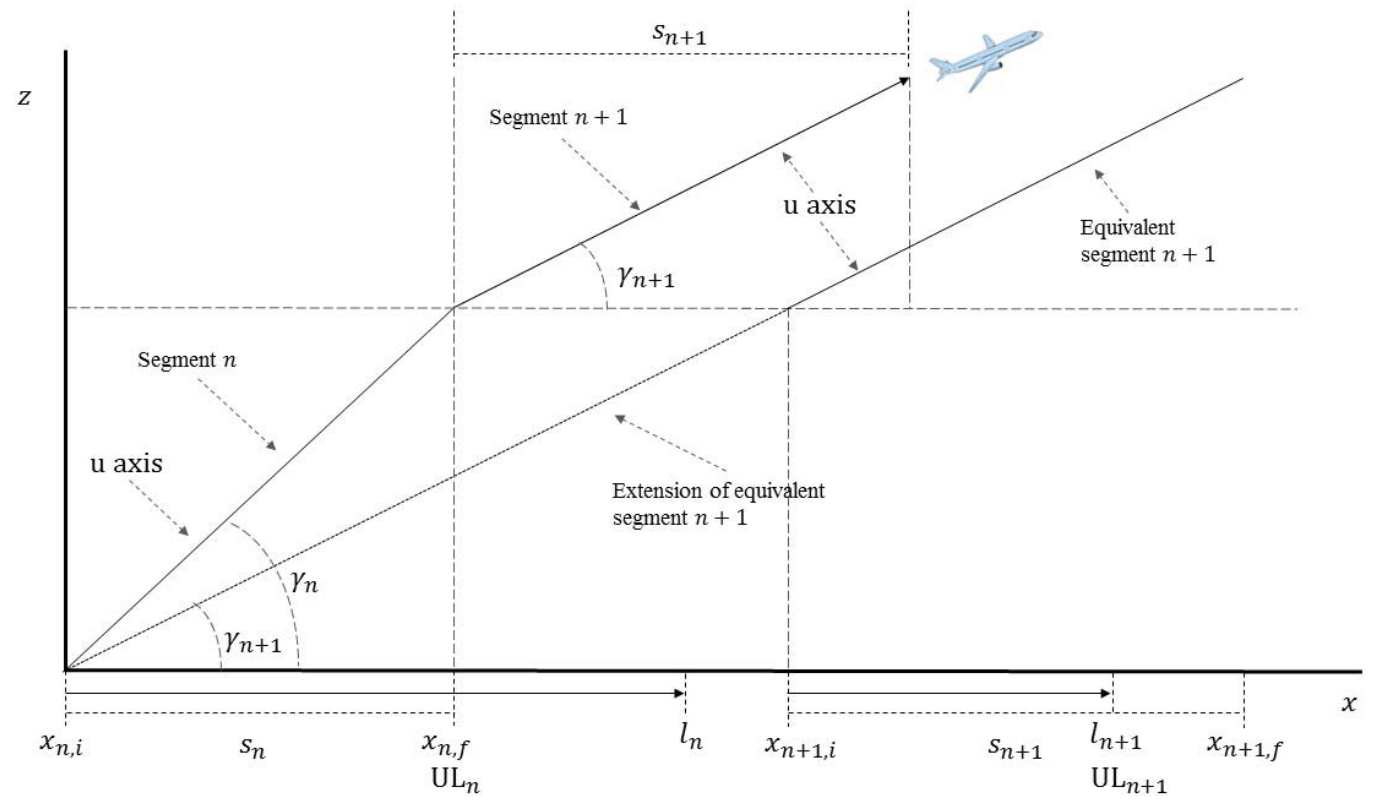

Fig. 3. (top) Definition of inclination angle $\left(\boldsymbol{\gamma}_{\boldsymbol{n}}\right)$, segment length $\left(s_{n}\right)$, segment start $\left(x_{n, i}\right)$ and end $\left(x_{n, f}\right)$ points, and the noise radius $\left(\mathrm{R}_{\mathrm{N} n}\right)$ for each $n$th flightpath segment; (bottom) Definition of the limits of integration in Eq. (4). (modified from [13]).

The area of a given noise contour is composed of contributions due to each of the various segments of the flightpath. Once the $\mathrm{R}_{\mathrm{N}}$ and $\gamma$ parameters are obtained for each segment in the flightpath, and assuming that all aircraft operations are straight-in and straightout and aligned with the runway axis, the noise contour area contributed by each flightpath segment is computed as:

$$
\mathrm{A}_{\mathrm{n}}\left(x_{n, i}, \mathrm{UL}_{n}\right)=\left[x \cdot \sqrt{\mathrm{R}_{\mathrm{N} n}^{2}-x^{2} \cdot \sin ^{2} \gamma_{n}}+\frac{\mathrm{R}_{\mathrm{N} n}^{2} \cdot \sin ^{-1}\left(\frac{x \cdot \sin \gamma_{n}}{\mathrm{R}_{\mathrm{N} n}}\right)}{\sin \gamma_{n}}\right]_{x_{n, i}}^{\mathrm{UL}_{n}}
$$


In Eq. (4), $x$ represents the waypoints defining the start and end of each $n t h$ flightpath segment (see Fig. 3 bottom). The first and second terms in Eq. (4) define the outer and inner parts, respectively, of the (cylindrical) noise surface around each $n t h$ flightpath segment once projected on the ground.

To compute the noise contour area contributed by each $n$th flightpath segment, and then compute the total noise contour area, the extension of the $n t h$ segment is assumed to intersect the ground horizontal plane $(\mathrm{z}=0)$ at the same origin (see Fig. 3 bottom). Thus, the limits of integration in Eq. (4) are defined as

$$
\begin{aligned}
& x_{n, i}=\frac{\sum_{\mathrm{k}=1}^{\mathrm{n}-1} s_{k} \tan \left(\gamma_{k}\right)}{\tan \left(\gamma_{n}\right)} \\
& x_{n, f}=x_{n, i}+s_{n}
\end{aligned}
$$

Finally, if $l_{n}=\frac{\mathrm{R}_{\mathrm{N} n}}{\sin \left(\gamma_{n}\right)}>x_{n, f}$, the noise contour is not ended and $\mathrm{UL}_{n}=x_{n, f}$, while if $l_{n}$ $<x_{n, f}$, the noise contour is ended and $\mathrm{UL}_{n}=l_{n}$ (for further details see [13]).

This model was used for estimating and projecting aviation noise impact for future scenarios in the UK, where various air traffic demand projections and technology options were evaluated [21].

\section{Simplified airport noise models for strategic environmental assessment of aviation}

\subsection{Certification noise based method and RANE vs. INM}

The performance of two methods frequently implemented for computing aviation noise outputs is discussed and compared to INM. These two methods are RANE [13], and the 
analytical method based on noise levels at certification measurement points [14], referred hereinafter as "Certification Noise Based Method" (both methods described above).

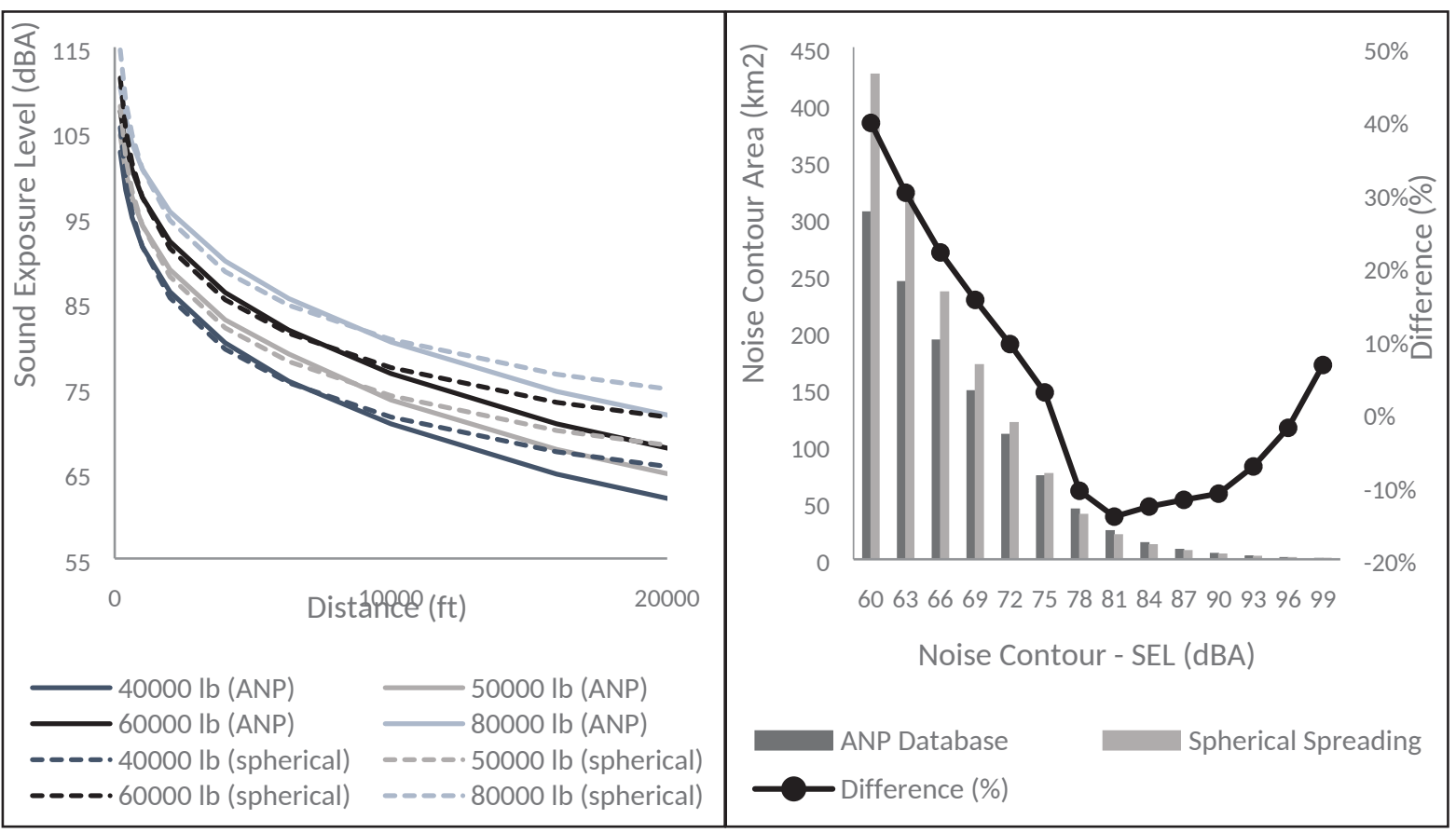

Fig. 4. (left) Noise Power Distance (NPD) curves of aircraft Airbus A380-841 for departure operations, as published in the Aircraft Noise and Performance (ANP) database (solid lines) and derived by extrapolation accounting for only spherical spreading (dotted lines); (right) Noise contour areas (departure) for Airbus A380-841 using NPD published in ANP database, and NPD derived by extrapolation accounting for only spherical spreading.

The certification noise based method for computing noise contour areas assumes only spherical propagation of the sound emitted by the aircraft. Therefore, this method does not account for factors such as atmospheric attenuation, Doppler effect, directivity and installation effects, and frequency spectra of the individual noise sources at the aircraft. The NPD published in the Aircraft Noise and Performance (ANP) database, which are used by detailed 
airport noise models (e.g. INM), are eminently empirical, and of course all the above factors are included in their derivation. Figure 4 (left) shows the NPD published in ANP database for the aircraft Airbus A380-841 (solid lines), and NPD derived by extrapolation only accounting for spherical wave spreading (dotted lines). For the derivation of this set of NPD, a given NPD standard distance (i.e. $1000 \mathrm{ft}$ ) is used as a reference point, and then the sound-level (dBA) at the remaining NPD standard distances is calculated using an extrapolation process accounting for only spherical wave spreading, but not for other factors such as atmospheric absorption, sound emission angles, and effective duration (all factors used for the computation of NPD published in ANP database [19]). As observed in Fig. 4 (left), regardless the power setting, the sound-level (SEL) decays with distance more rapidly for the case of empirical NPD (ANP database) than for the case of NPD derived only accounting for spherical propagation. This result might be explained by atmospheric absorption effects significantly reducing the highfrequency sound-levels at large distances [19] (this reduction of high-frequency sound-levels is magnified for A-weighted sound-levels, i.e. SEL in $\mathrm{dBA}$ ). These atmospheric effects are either directly or indirectly accounted for in [19] for the obtaining of NPD published in ANP (depending on the procedure used for NPD computation). For the conditions evaluated in this paper (see above), an overestimation of up to $5 \mathrm{~dB}$ in SEL (at a distance of $25000 \mathrm{ft}$ ) is observed in NPD only accounting for spherical spreading.

Moreover, as stated by Powell [14], the certification noise based method assumes constant power along the flightpath, and consequently constant aircraft noise output. Of course, this is not true in daily aircraft departure operations, where at a given distance from the start-of-roll point the power is drastically reduced (power cut-back) in order to preserve engine performance margin and save engine maintenance costs, but also to reduce aircraft emissions and noise. Both sets of NPD (published in ANP database, and derived by extrapolation only accounting for spherical spreading) were implemented for computing noise contour areas for 
the aircraft A380-841, from 60 dBA- to 99 dBA-SEL (Fig. 4 (right)). For noise contours close to the runway (72 dBA- to $99 \mathrm{dBA}-\mathrm{SEL}$ ) the areas within the contour estimated with NPD only accounting for spherical spreading are within an interval of $-15 \%-+10 \%$ as compared to empirical NPD. Differences of 0.6 and $0.8 \mathrm{~dB}$ are also observed for sideline and flyover certification points respectively, when implementing both sets of NPD. However, as observed in Fig. 4 (right) when further away from the runway significant differences take place (up to $40 \%$ for $60 \mathrm{dBA}-\mathrm{SEL}$ noise contour). These differences in noise contour areas for the noise contours calculated (Fig. 4 (right)) are consistent with the differences in NPD shown in Fig. 4 (left).

A typical use of simplified airport noise models is the estimation of noise impact (usually addressed by calculating noise contour areas) of future aviation scenarios, when different air traffic demands and technology options are evaluated [10,13,21]. An example of the performance of the certification noise based method for computing changes in noise contour areas is shown in Fig. 5. This figure shows the change in $57 \mathrm{dBA}-\mathrm{L}_{\mathrm{Aeq}, 16 \mathrm{~h}}$ contour area calculated with the certification noise based method, and with INM for a relative number of aircraft movements (F). ${ }^{1}$ The aircraft used for these calculation is the Boeing 747-8, with $\mathrm{F}=$ 1 to 5 (noise contour area with $\mathrm{F}=1$ set at the same value for all methods). As observed in Fig. 5, and in line with the above results, the certification noise based method significantly overestimates (as compared to INM) the change in noise contour area when the relative number of movements increases (about $40 \%$ overestimation with $\mathrm{F}=5$ ).

\footnotetext{
${ }^{1}$ From a baseline scenario with an arbitrary number of aircraft movements (e.g. 100 Landing and Take-off movements -LTOs), referred as F = 1, the number of aircraft movements is increased by a factor of $x$ compared to that baseline scenario, up to 5 times the baseline number of aircraft movements, i.e. $F=5$.
} 


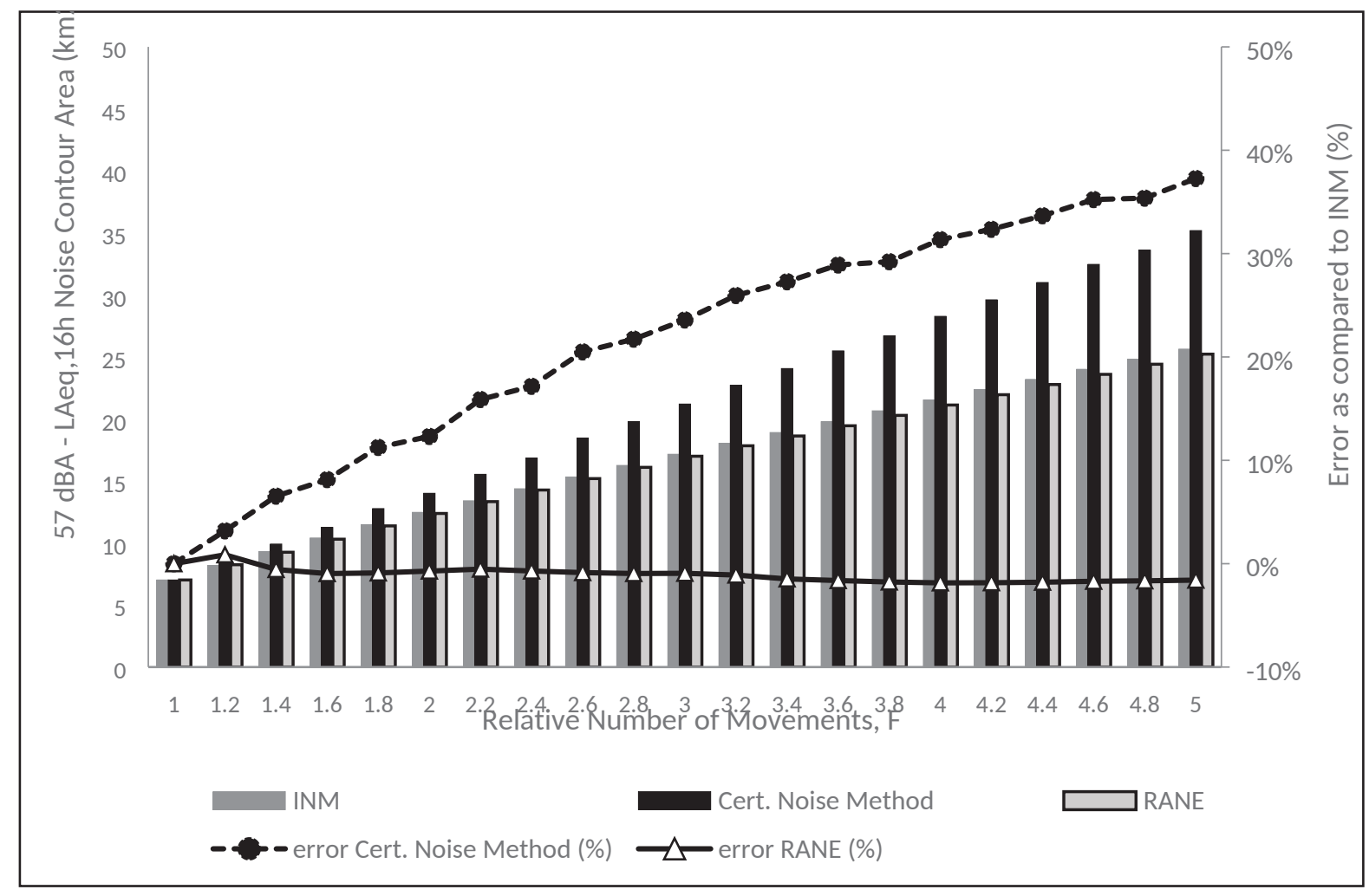

Fig. 5. Change in $57 \mathrm{dBA}-\mathrm{L}_{\mathrm{Aeq}, 16 \mathrm{~h}}$ contour area calculated with $\mathrm{INM}$, RANE and the Certification Noise based Method for a relative number of aircraft movements ( $\mathrm{F}=1$ to 5 ). Also shown the error as compared to INM.

The performance of RANE for estimating changes in noise contour areas with a varying number of movements is also shown in Fig. 5. For the specific case shown in Fig. 5, when the relative number of operations is increased, RANE estimates the change in noise contour area with no differences compared to INM exceeding $\pm 2 \%$. In RANE, the NPD database published in ANP is used for computing an "energy-equivalent" or Noise Radius, $\mathrm{R}_{\mathrm{N}}$ on which is based the calculation of noise contour areas (as described above). The analytical method used in RANE requires also the operational profiles of all the aircraft flying along a given flightpath, so an "average" trajectory for the whole fleet can be calculated. This data, in the form of an "equivalent" inclination angle common for the whole aircraft fleet $(\gamma)$ is used in equation (4) 
for the calculation of noise contour areas. Therefore, any change in the operational procedures of the aircraft fleet is considered by RANE when computing noise contour areas (see [13] for a detailed description).

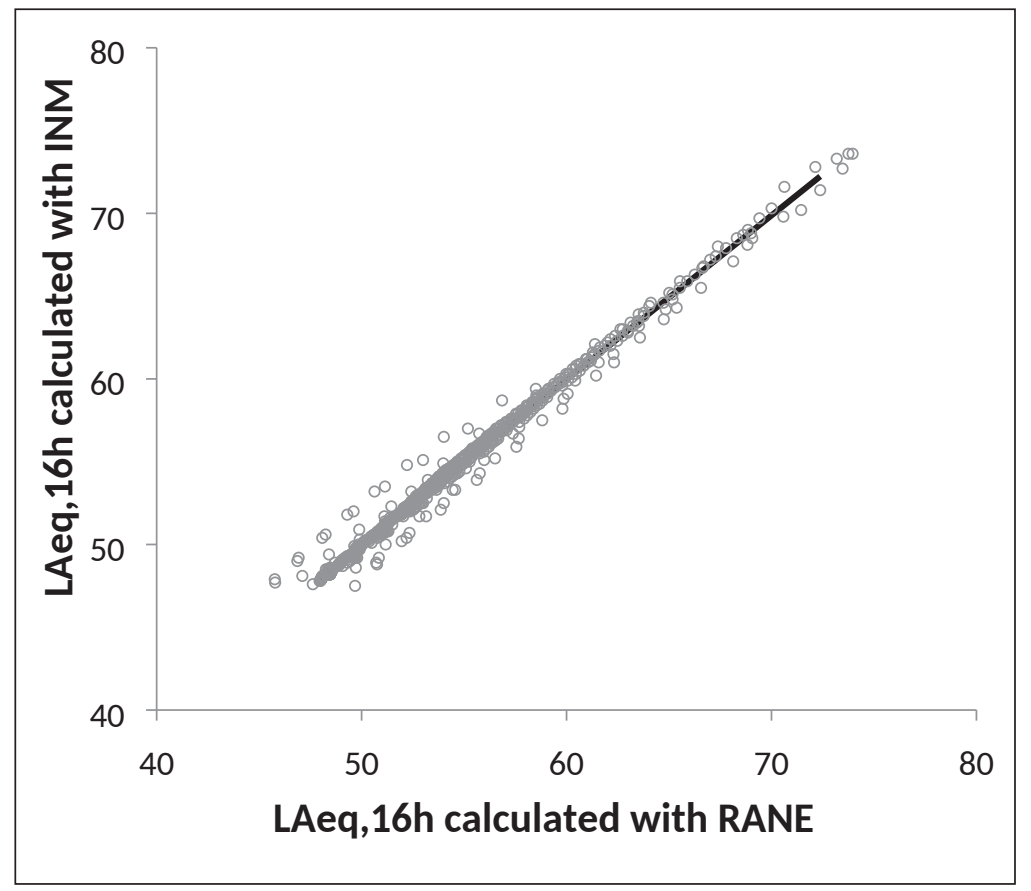

Fig. 6. Scatter diagram of $L_{A e q, 16 h}$ calculated using INM and RANE for a fleet composed of 4 aircraft (CRJ-900, 737-800, A330 and 747-400) with 50 movements each (reprinted from [13]).

If there is no change in the spatial distribution of flight tracks, the changes in noise contour with, for instance, changes in aircraft movements are at first order independent from changes in shape, and consequently only changes in noise contour area take place. This assumption was validated [13] by calculating $\mathrm{L}_{\text {Aeq,16h }}$ values in a grid of $250 \times 250 \mathrm{~m}$ using INM and RANE, for an aircraft fleet composed of 4 aircraft (Regional Jet: CRJ-900, Single Aisle: Boeing 737-800, Twin Aisle - 2 engines: Airbus A330, and Twin Aisle -4 engines: Boeing 747-400) with 50 movements each (Fig. 6 ). As shown in Fig. 6 a correlation coefficient 
of 0.99 was found for this specific scenario. This validation demonstrates the capability of RANE for estimating the change in noise contour areas with variations in the aircraft fleet (i.e. changes in air traffic movements, fleet composition, and introduction of new aircraft).

\subsection{Discussion on advantages and limitations of simplified airport noise models}

The simplified airport noise models are devised to provide a tool for the rapid assessment of aviation noise impact for a number of scenarios, and also for performing parametric studies where 'optimal' solutions for minimizing noise impact are explored. If reduced input data requirements (as compared to detailed airport noise models) and compatibility with other emissions and economic models are ensured, the simplified noise models will support a much more integrated and multi-disciplinary strategic environmental assessment of aviation scenarios.

The implementation of certification noise based methods $[11,14,15]$ allows an easy and straightforward estimation of noise outputs, using a reduced input data. However, the applicability of these methods is usually misinterpreted. As stated by Powell [14], these methods assume constant power setting (and therefore constant noise output) along the flightpath, and a spherical propagation of the sound emitted by the aircraft to the ground. This assumption is not valid for real-life aircraft operations, where climbing conditions, flap settings, airspeed, and consequently power setting (i.e. power cut-back) significantly varies along the flightpath. Also, the sound propagation from the aircraft is a complex process where different phenomena such as atmospheric attenuation, directivity and installation effects, and Doppler effect plays an important role (see Fig. 4 (left)). For all these reasons, the sound-levels measured at the certifications points, defining what could be called a "certification noise contour", should not be extrapolated for estimating other noise contours (especially those more 
distant from the runway). When this extrapolation is carried out significant deviations, from detailed airport noise models (INM), are observed in the estimation of noise contour areas (Fig. 4 (right) and Fig. 5).

On the other hand, Dikshit and Crossley [11] state that the impact of new technology can be investigated by adjusting the certification noise levels. This statement might not be true for all conditions. The noise contour of a given aircraft is defined by the noise emitted at source but also by the operational profile. For instance, we could have a novel aircraft which is substantially quieter but has a significantly worse operational profile (as compared to a current aircraft), requiring more thrust and with worse climbing performance (i.e. this aircraft is assumed to be significantly heavier). In this specific case, as compared to a current aircraft, the noise measured at the certification points might be similar, but important reductions in the noise contour area might be observed. The certification noise based methods can be therefore useful for estimating the overall change in noise energy emitted by an aircraft fleet with the introduction of novel technologies, but should not be used for quantifying changes in noise contour areas.

Bernardo et al. [17] developed a simplified model based on the pre-calculation and logarithmic addition of single-event aircraft grids for computing airport-level noise grids, from which both noise contours and noise contour areas can be calculated. This model is able to compute noise contours for complex runway scenarios. However, multi-disciplinary strategic environmental assessment studies, such as the strategic evaluation of the environmental impact of different aircraft technologies are usually addressed at a national or regional level, and not at an airport specific level. Also, at early stages in the decision process these studies do not require contour shape information, and benefits in terms of noise impact might be simply approximated by changes in noise contour areas. The RANE model (stage 1 version) was developed to accomplish with such purposes, i.e. computing noise outputs to support an 
integrated and multi-disciplinary strategic environmental assessment of aviation [13]. Unlike other models which use the equivalency assumption [10,16,17] (i.e. a new aircraft is defined in terms of its equivalent operations of the current baseline aircraft), RANE was developed to be coupled with technology evaluators (e.g. [22,23]), which will provide NPD records for novel aircraft concepts. Because, among others, the different frequency spectra, directivity characteristics, and operational behavior of novel aircraft as compared to current types, the RANE's approach seems more adequate to address policy decisions about which future technology platforms would ensure a better environmental performance.

\section{Validation of assumptions of simplified airport noise models}

This section examines and discusses the validity of two common simplifications assumed in most of the simplified airport noise models reviewed, i.e. the straight-out trajectory and the use of generic aircraft as representative of each aircraft category.

\subsection{Straight-out vs. turning flightpath}

The validity of the straight-out trajectory assumption was evaluated using a set of experimental conditions: (i) the average number of air traffic movements in Gatwick airport in 2015 by aircraft type [24] was distributed between two flight tracks: a straight-out flightpath, and a turning flightpath; (ii) the percentage of air traffic movements in the turning flightpath was varied from 0 to $100 \%$, in $25 \%$ steps; (iii) four turning angles in the turning flightpath were considered, i.e. 45, 90, 135 and 180 degrees; (iv) only departure operations were considered. INM was used for computing both noise contours and noise contour areas $(55,60$ and 65 dBA-DNL) for each experimental condition as described. 


\section{Table 1}

Change in noise contour area (as compared to a straight-out flightpath with $100 \%$ of the movements) when varying the percentage of movements in the turning flightpath and the turning angle.

\begin{tabular}{|c|c|c|c|c|c|}
\hline $\begin{array}{l}\text { Straight-out flightpath } \\
\text { (\% movements) }\end{array}$ & $\begin{array}{c}\text { Turning flightpath (\% } \\
\text { movements) }\end{array}$ & $\begin{array}{c}\text { Turning } \\
\text { angle (deg) }\end{array}$ & $\begin{array}{l}55 \text { dBA- } \\
\text { DNL }\end{array}$ & $\begin{array}{l}\text { 60 dBA- } \\
\text { DNL }\end{array}$ & $\begin{array}{l}65 \mathrm{dBA}- \\
\text { DNL }\end{array}$ \\
\hline \multirow{4}{*}{$75 \%$} & \multirow{4}{*}{$25 \%$} & 45 & $-6 \%$ & $-5 \%$ & $0 \%$ \\
\hline & & 90 & $-8 \%$ & $-6 \%$ & $0 \%$ \\
\hline & & 135 & $-7 \%$ & $-6 \%$ & $0 \%$ \\
\hline & & 180 & $-6 \%$ & $-5 \%$ & $0 \%$ \\
\hline \multirow{4}{*}{$50 \%$} & \multirow{4}{*}{$50 \%$} & 45 & $-8 \%$ & $-7 \%$ & $0 \%$ \\
\hline & & 90 & $-10 \%$ & $-8 \%$ & $0 \%$ \\
\hline & & 135 & $-10 \%$ & $-7 \%$ & $0 \%$ \\
\hline & & 180 & $-7 \%$ & $-7 \%$ & $1 \%$ \\
\hline \multirow{4}{*}{$25 \%$} & \multirow{4}{*}{$75 \%$} & 45 & $-6 \%$ & $-5 \%$ & $0 \%$ \\
\hline & & 90 & $-8 \%$ & $-5 \%$ & $1 \%$ \\
\hline & & 135 & $-8 \%$ & $-4 \%$ & $1 \%$ \\
\hline & & 180 & $-4 \%$ & $-3 \%$ & $1 \%$ \\
\hline \multirow{4}{*}{$0 \%$} & \multirow{4}{*}{$100 \%$} & 45 & $0 \%$ & $0 \%$ & $1 \%$ \\
\hline & & 90 & $0 \%$ & $0 \%$ & $1 \%$ \\
\hline & & 135 & $0 \%$ & $2 \%$ & $1 \%$ \\
\hline & & 180 & $\%$ & $4 \%$ & $2 \%$ \\
\hline
\end{tabular}

Table 1 shows the change in noise contour area when varying the percentage of movements in the turning flightpath and the turning angle, as compared to a straight-out flightpath with $100 \%$ of the movements. As shown in Table 1, for these specific experimental conditions, the error (in noise contour area estimation) made with the straightened-out trajectory assumption reaches an absolute maximum value of $10 \%, 8 \%$ and $2 \%$ for the 55,60 and 65 dBA-DNL respectively. These results suggest that the straight-out trajectory assumption allows a good approximation when computing noise contour areas, even under extreme conditions of spatial distribution of flight movements.

Fig. 7 shows the 55 (top left), 60 (top right) and 65 (bottom) dBA-DNL noise contour when varying the turning angle from 0 to 180 degrees; in this case, $50 \%$ of the aircraft flew 
along the straight-out flightpath and the other $50 \%$ along the turning flightpath. Unlike for the estimation of noise contour areas, the assumption of straight-out trajectories can lead to significant errors when computing noise contours, i.e. for calculating the spatial distribution of sound-levels. This is particularly evident for low DNL noise contours (Fig. 7, top left and right), which might be used as thresholds for community noise annoyance.

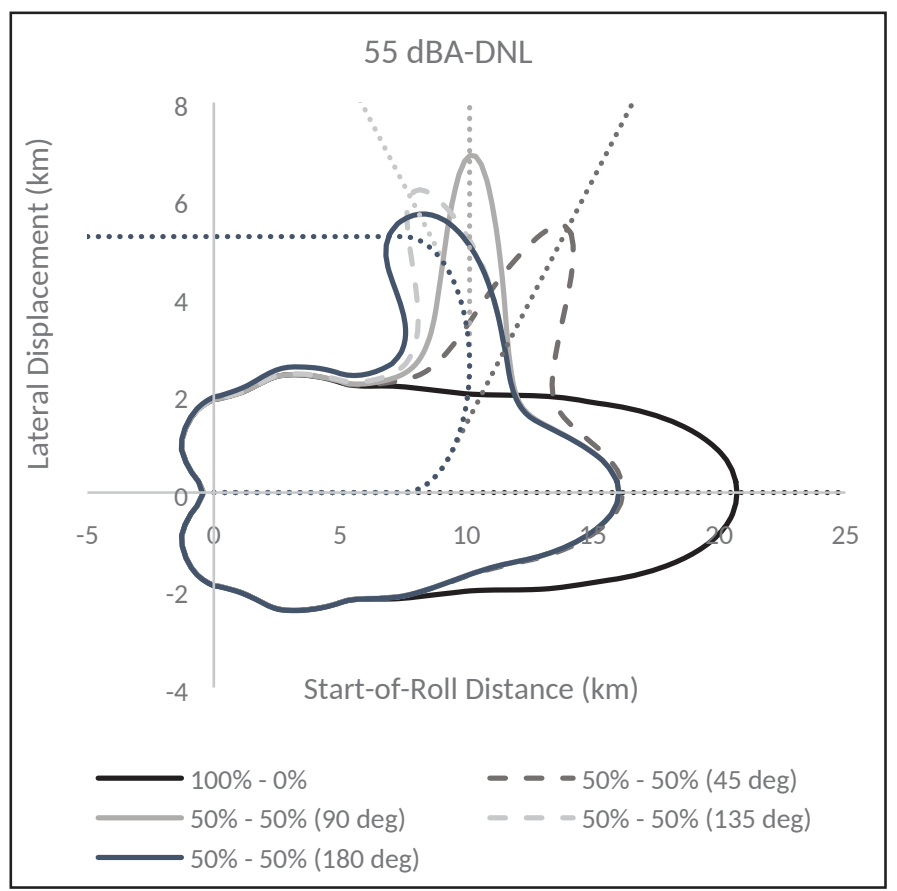




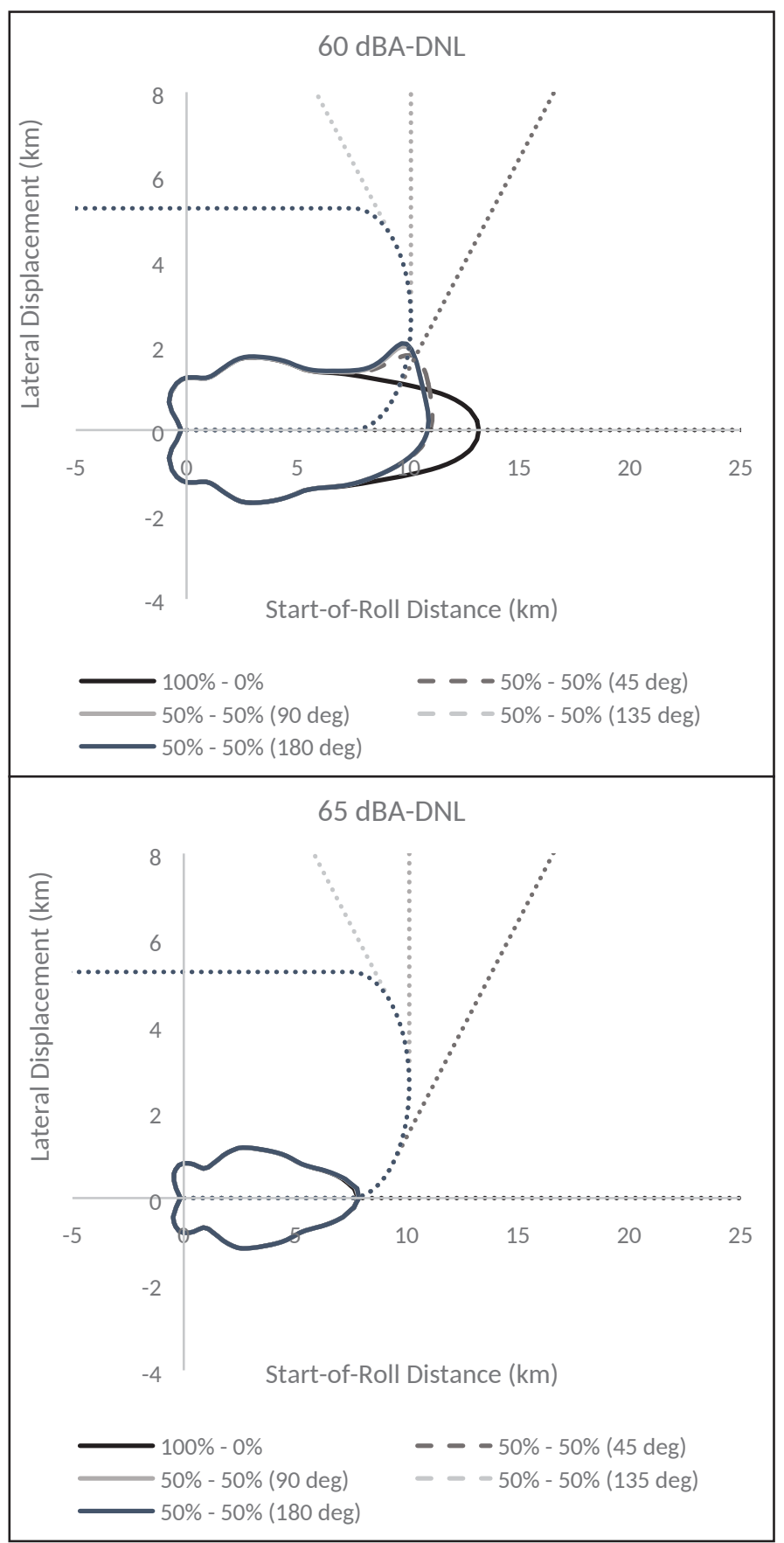

Fig. 7. Noise contours (55 dBA-DNL - top, 60 dBA-DNL - middle, and 65 dBA-DNL bottom) varying the turning angle with $50 \%$ movements in both the straight-out flightpath and the turning flightpath. The noise contour for $100 \%$ movements in the straight-out flightpath (black line), and the flight tracks (dotted lines) are shown as reference. 
As indicated above, within the context of strategic assessment of aviation scenarios, simplified airport noise models are usually used for calculating changes in noise contour areas with changes in some input parameters, e.g. air traffic movements. Table 2 shows that changes in noise contour areas when doubling the number of movements can be calculated assuming a straight-out trajectory with an absolute maximum error of 13\%,3\% and 3\% for the 55, 60 and 65 dBA-DNL noise contours respectively. For these calculations the straight-out trajectory (with $100 \%$ aircraft movements) was compared to a 180 degrees turning trajectory with $50 \%$ and $100 \%$ of aircraft movements.

\section{Table 2}

Delta noise contour area when doubling the number of movements. In brackets it is shown the error of assuming a straight-out flightpath as compared to the other two conditions tested.

\begin{tabular}{|c|c|c|c|c|c|c|}
\hline Condition & $\begin{array}{l}\text { Straight-out } \\
\text { flightpath (\% } \\
\text { movements) }\end{array}$ & $\begin{array}{l}\text { Turning flightpath } \\
\text { (\% movements) }\end{array}$ & $\begin{array}{l}\text { Turning } \\
\text { angle (deg) }\end{array}$ & $\begin{array}{l}55 \text { dBA- } \\
\text { DNL }\end{array}$ & $\begin{array}{l}\text { 60 dBA- } \\
\text { DNL }\end{array}$ & $\begin{array}{l}65 \text { dBA- } \\
\text { DNL }\end{array}$ \\
\hline 0 & $100 \%$ & $0 \%$ & n.a. & $\begin{array}{l}1.51 \\
(1:-13 / \\
2:+8 \%) \\
\end{array}$ & $\begin{array}{l}1.72 \\
(1:+3 / \\
2:+1 \%) \\
\end{array}$ & $\begin{array}{l}1.77 \\
(1:+3 / \\
2:-2 \%)\end{array}$ \\
\hline 1 & $50 \%$ & $50 \%$ & 180 & 1.75 & 1.66 & 1.72 \\
\hline 2 & $0 \%$ & $100 \%$ & 180 & 1.40 & 1.70 & 1.80 \\
\hline
\end{tabular}

Although not all the potential conditions in terms of operational volumes, fleet mixes and spatial distribution of aircraft movements were tested, this section examined some highly representative, and also extreme, conditions. In any case, and based on the specific conditions tested (e.g. London Gatwick aircraft fleet and movements), the results above presented 
demonstrate that the straight-out trajectory is a valid approximation for computing noise contour areas, and changes in noise contour areas.

\subsection{Sound intensity of departure vs. approach operations}

The average number of air traffic movements, by aircraft type, in Heathrow airport in 2015 [25] was used for computing the 55, 60 and 65 dBA-DNL noise contours. Both departure and approach operations were considered. All approach operations flew along a straight-out flightpath. For the case of departure operations, $60 \%$ flew along a straight-out flightpath, and the remaining $40 \%$ flew along a 180 degrees turning flightpath.

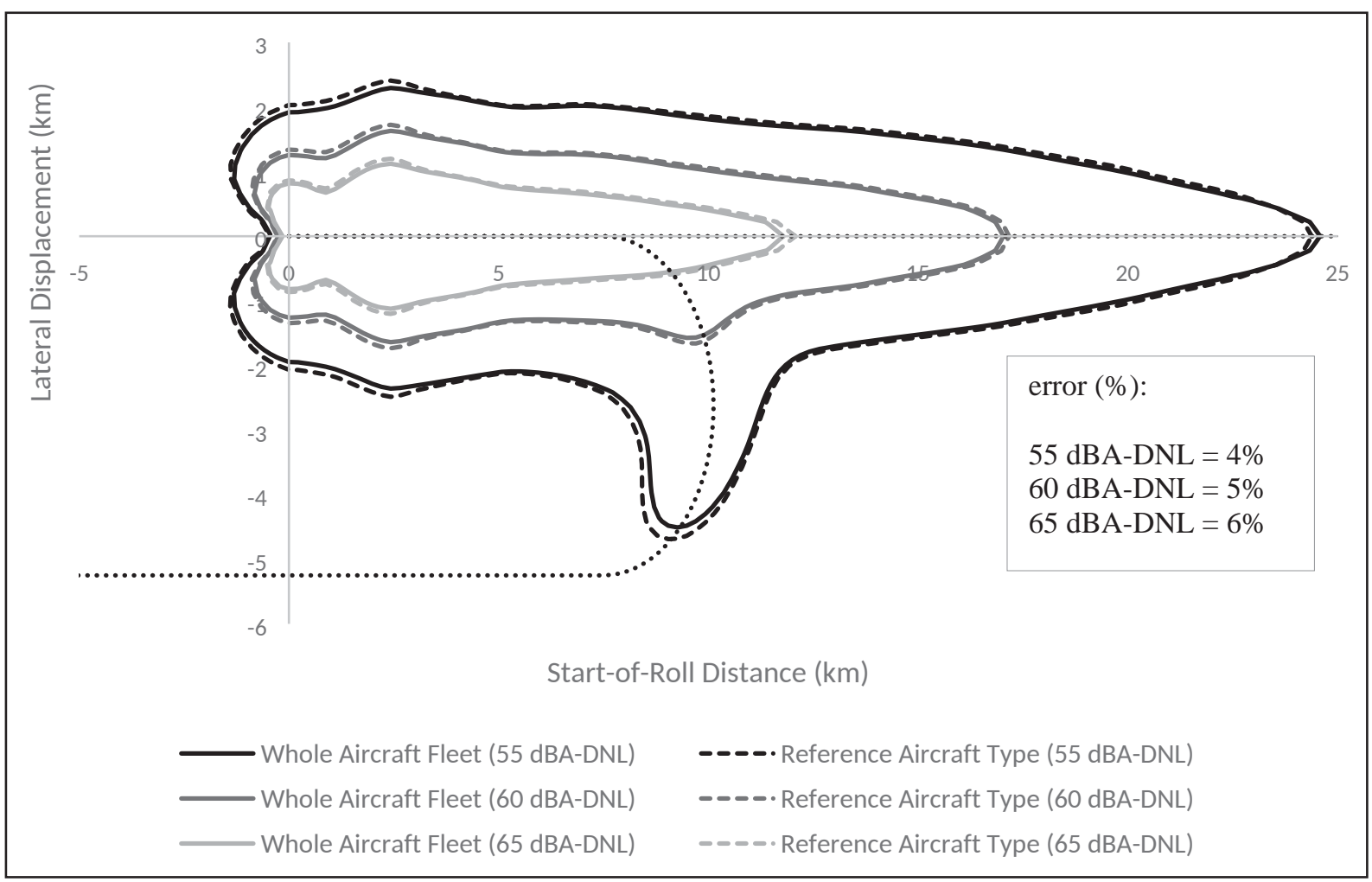

Fig. 8. 55, 60 and 65 dBA-DNL noise contours using the whole aircraft fleet in Heathrow (solid lines), and using only a representative aircraft for each aircraft category (dotted lines). The flight tracks (black dotted lines) are shown as reference. 
For validating the assumption of using generic aircraft as representative of each aircraft type, when calculating noise contour and noise contour areas, the different aircraft composing the aircraft fleet of Heathrow airport in 2015 were classified into 9 aircraft categories according to Sustainable Aviation [26]. Then, a representative aircraft for each category, i.e. aircraft with the highest number of movements, was selected:

- Small Regional Jets: CRJ-701

- Large Regional Jets: Embraer 190

- Small Single Aisle: A319-131

- Medium Single Aisle: A320-232

- Large Single Aisle: A321-232

- Small Twin Aisle: 787-8 Dreamliner

- Medium Twin Aisle: 767-300

- Large Twin Aisle: 777-300

- Very Large: $747-400$

All the flight movements within each aircraft category were assigned to the corresponding representative aircraft, and then, the noise contour and noise contour areas were calculated as described above.

As shown in Fig. 8, the noise contours calculated for the whole aircraft fleet in Heathrow (with 50 aircraft types) were accurately replicated using only the 9 representative aircraft above indicated. The error in the computation of noise contour areas using this approximation was found negligible in comparison with the total noise contour area, in the range $4 \%$ (55 dBA-DNL) to $6 \%$ (65 dBA-DNL). 
On the other hand, this approximation was found valid for the calculation of changes in noise contour areas with variations in air traffic movements. For instance, the error made with this approximation for the calculation of changes in noise contour areas when doubling the number of movements was about $1 \%$.

Although the results above presented demonstrate the validity of this simplification to calculate noise contours and noise contour areas, for the specific conditions tested in this work, further work will be required for defining generic aircraft types considering other aircraft emissions, and establishing representative stage lengths.

\section{Conclusions}

Within the framework of multi-disciplinary strategic environmental impact assessment of aviation, this paper analyses the applicability and discusses the unavoidable limitations and advantages of some of the simplified airport noise models more often cited in the literature. This paper demonstrates that the implementation of methods based on certification noise values leads to significant deviations in the estimation of noise contour areas (especially those more distant from the runway), as compared to detailed airport noise models (such as INM). For strategic environmental assessment of aviation, simplified airport noise models based on certification values should not be used for estimating changes in noise contour areas, but their implementation should be restricted to the quantification of overall changes in the noise energy emitted by aviation under specific circumstances (e.g. fleet composition, air traffic demand, etc.). For strategic environmental assessment studies, usually addressed at a national or regional level, noise contour shape information is not required, and benefits or disbenefits in terms of noise impact might be simply approximated by changes in noise contour areas. For this purpose, simplified airport noise models developed to be coupled with technology 
evaluators, such as RANE model, are useful tools for informing policy decisions about which future technology platforms would ensure a better environmental performance.

On the other hand, for the specific conditions tested in this work, the straight-out trajectory assumption is found as a valid approximation for the computation of both noise contour areas and changes in noise contour areas. However, important errors are observed when this simplification is used for computing noise contours, especially for noise contours usually used as threshold for community noise annoyance (i.e. 55 and 60 dBA-DNL noise contours).

Based on the results presented in this paper, the reduction of the aircraft fleet to a number of generic or representative aircraft types seems to be a valid approximation for computing noise outputs around airports. With this simplification both noise contours and noise contour areas are computed with minimum uncertainly. These results are based on a set of specific conditions, and of course, further work will be required for defining generic aircraft types to be used in multi-disciplinary strategic environmental assessment of aviation.

\section{Acknowledgements}

This work was partly supported by the Engineering and Physical Science Research Council (grant number EP/M026868/1), and by Innovate UK (Grant No. TSB/113086). 


\section{References}

[1] Department for Transport. UK aviation forecast, Technical report, London, UK; 2013.

[2] Eurocontrol. Challenges of growth, Task 7: European air traffic in 2050, Technical report, Brussels, Belgium; 2013.

[3] Airbus. Global market forecast: Mapping demand 2016 / 2035, Technical report, Blagnac, France; 2016.

[4] European Commission. Flightpath 2050: Europe's vision for aviation, Technical report, Luxembourg; 2011

[5] Collier, F.S. NASA aeronautics environmentally responsible aviation project, Oral presentation at the 50 ${ }^{\text {th }}$ AIAA Aerospace Sciences Meeting, Nashville, USA; 2012.

[6] Khardi, S., Abdallah, L. Optimization approaches of aircraft flight path reducing noise: Comparison of modeling methods. Appl Acoust 2012;73:291-301.

[7] Graham, W.R., Hall, C.A., Vera Morales, M. The potential of future aircraft technology for noise and pollutant emissions reduction. Transp Policy 2014;34:36-51.

[8] Federal Aviation Administration. Integrated Noise Model (INM) [version 7.0], Technical manual, Rept. FAA-AEE-08-01, Washington, D.C., USA; 2008.

[9] Ollerhead, B.J., Rhodes, D.P., Viinikainen, M.S., Monkman, D.J., Woodley, A.C. The UK civil aircraft noise contour model ANCON: Improvements in version 2, Rep. 9842, Environmental Research and Consultancy Department, UK Civil Aviation Authority, London, UK; 1999.

[10] Bernardo, J.E., Kirby, M.R., Mavris, D. Probabilistic assessment of fleet-level noise impacts of projected technology improvements, J. Air Transp Manage 2016;57:26-42. 
[11] Dikshit, P.N., Crossley, W.A. Airport noise model suitable for fleet-level studies. In Proceedings of the $9^{\text {th }}$ AIAA Aviation Technology, Integration, and Operations Conference (ATIO), South Carolina, USA; 2009.

[12] Dray, L., Krammer, P., Doyme, K., Wang, B., Al Zayat, K., O’Sullivan, A., Schafer, A. AIM2015: Validation and initial results from an open-source aviation systems model. In Proceedings of the $21^{\text {st }}$ Air Transport Research Society Conference (ATRS), Antwerp, Belgium; 2017.

[13] Torija, A.J., Self, R.H., Flindell, I.H. A model for the rapid assessment of the impact of aviation noise near airports. J Acoust Soc Am 2017;141:981-995.

[14] Powell, C.A. Relationship between aircraft noise contour area and noise levels at certification points. Technical report, NASA/TM-2003-212649, Virginia, USA; 2003.

[15] Tetzloff, I.J., Crossley, W.A. Measuring systemwide impacts of new aircraft on the environment. J Aircraft 2014;51:1483-1489.

[16] “AEM V. 7.0-User's Manual," Federal Aviation Administration, Office of Environment and Energy, Washington, D.C., Oct. 2012, http://www.faa.gov/about/office_org/headquarters_offices/apl/research/models/aem_ model/media/AEM_70c_UsersGuide.pdf.

[17] Bernardo, J.E., Kirby, M.R., Mavris, D. Development of a rapid fleet-level noise computation, J. Aircraft 2015;52:721-733.

[18] Li, J., Chen, N., Ng, H.K., Sridhar, B. Simple tool for aircraft noise-reduction route design. In Proceedings of the $15^{\text {th }}$ AIAA Aviation Technology, Integration, and Operations Conference (ATIO), Dallas, USA; 2015. 
[19] Society of Automotive Engineers. Procedure for the calculation of airplane noise in the vicinity of airports. Technical report, AIR-1845A; 2012.

[20] Zaporoshets, O.I., Tokarev, V.I. Aircraft noise modelling for environmental assessment around airports. Appl Acoust 1998;55(2):99-127.

[21] Torija, A.J., Self, R.H., Flindell, I.H. Evolution of noise metrics in future aviation scenarios in the UK. In Proceedings of the $23^{\text {rd }}$ International Congress on Sound and Vibration (ICSV), Athens, Greece; 2016.

[22] Synodinos, A., Self, R., Torija, A., Flindell, I. A new method for estimating community noise changes due to aircraft technology variations. In Proceedings of the $23^{\text {rd }}$ International Congress on Sound and Vibration (ICSV), Athens, Greece; 2016.

[23] Synodinos, A.P., Self, R.H., Torija, A.J. Framework for predicting Noise-PowerDistance curves for novel aircraft designs. J. Aircraft 2017, accessed September 19, 2017, doi: http://arc.aiaa.org/doi/abs/10.2514/1.C034466.

[24] Lee, J., Cebrian, G., Edmonds, L., Patel, J., Rhodes, D. Noise exposure contours for Gatwick airport 2015. Technical report, ERCD 1602, London, UK; 2017.

[25] Lee, J., Cebrian, G., Edmonds, L., Patel, J., Rhodes, D. Noise exposure contours for Heathrow airport 2015. Technical report, ERCD 1601, London, UK; 2017.

[26] Sustainable Aviation. The SA noise road-map: A blueprint for managing noise from aviation sources to 2050. Technical Report, London, UK; 2013. 